\title{
Patterns of Growth-Biomimetics and Architectural Design
}

\author{
Petra Gruber ${ }^{1, *}$ and Barbara Imhof ${ }^{2}$ \\ 1 Mary Schiller Myers School of Art and Department of Biology, Biomimicry Research and Innovation \\ Center BRIC, University of Akron, Akron, OH 44325, USA \\ 2 Liquifer Systems Group, Vienna 1020, Austria; bimhof@liquifer.at \\ * Correspondence: pgruber@uakron.edu; Tel.: +133-0940-9885
}

Academic Editors: Maibritt Pedersen Zari and David Arditi

Received: 30 October 2016; Accepted: 28 March 2017; Published: 4 April 2017

\begin{abstract}
This paper discusses the approach of biomimetic design in architecture applied to the theme of growth in biology by taking two exemplary research projects at the intersection of arts and sciences. The first project, 'Biornametics', dealt with patterns from nature; the second project 'Growing as Building (GrAB)' took on biological growth as a specific theme for the transfer to architecture and the arts. Within a timeframe of five years (2011-2015), the research was conducted under the Program for Arts-based Research PEEK (Programm zur Entwicklung und Erschliessung der Künste) of the Austrian Science Fund FWF (Fonds zur Förderung der wissenschaftlichen Forschung). The underlying hypothesis was that growth processes in nature have not been studied for transfer into technology and architecture yet and that, with advanced software tools, promising applications could be found. To ensure a high degree of innovation, this research was done with an interdisciplinary team of architects, engineers, and scientists (mainly biologists) to lay the groundwork for future product-oriented technological solutions. Growth, as one of the important characteristics of living organisms, is used as a frame for research into systems and principles that shall deliver innovative and sustainable solutions in architecture and the arts. Biomimetics as a methodology was used to create and guide information transfer from the life sciences to innovative proto-architectural solutions. The research aimed at transferring qualities present in biological growth; for example, adaptiveness, exploration, or local resource harvesting into technical design and production processes. In contrast to our current building construction, implementing principles of growth could potentially transform building towards a more integrated and sustainable setting, a new living architecture. Tools and methods, especially Quality Function Deployment (QFD) for matching biological role models with growth principles and architecturally desired functions and a Biolab as an experimentation platform are presented. Three main experimental trajectories were explored that matched the objectives of the research: (1) Transfer from biology into architecture, namely self-growing structures (proto-steps in form of a mobile 3D printer working with local material); (2) Integration of biology into material systems, namely fragmented waste matter grown into one solid building material (mycelium); and (3) Interventions in existing architecture, namely optimization of 3D path-finding through a single cell organism (slime mold).
\end{abstract}

Keywords: biomimetics; architecture; growth processes; slime mold; mycelium material; 3D printer; morphogenesis

\section{Introduction}

This paper discusses the approach of biomimetic design in architecture applied to the theme of growth in biology by taking two exemplary research projects at the intersection of arts and sciences. The first project, 'Biornametics', dealt with patterns from nature; the second project 'Growing as 
Building (GrAB) took on biological growth as a specific theme for the transfer to architecture and the arts.

Growing interest in the intersection of arts and sciences in recent years has led to a number of research programs and opportunities to explore transdisciplinarity in architectural design. 'Artistic research' and 'Research by design' acknowledge the investigation of possible futures as valid scientific approaches, and scientific findings are increasingly taken up and translated by artists and designers [1]. Efforts to create mutual influence between arts and sciences target the reconnection of highly specialized fields and the common exploration of yet unknown areas.

Biological research and role models from nature increasingly inform technological solutions, and architects and engineers also look to nature for inspiration. The investigation of the overlaps between the fields of biology and technology, biomimetics, has gained ground in research and development [2-4]. Signs of life, as defined by the life sciences, are introduced into former static and unresponsive buildings so that sensing, reactivity, adaptation, and also evolutionary development are found in contemporary architectural design $[5,6]$. The exploration of the intersections between biology and architecture has been the research field of the authors in previous projects [7-9]. Research on patterns of nature for architecture has revealed the potential of looking at growth in biology to inspire new planning and building processes [10].

The disadvantages of contemporary planning and building practices are manifold. Building construction is often a messy, mostly centrally controlled process that requires exhaustive organization and resources that are transported over global distances as well as being produced by unsustainable, often toxic, and also socially irresponsible processes. The resulting buildings and the sites are unusable during the process and usually also influence their surroundings in a negative way [11]. It seems that especially with large building tasks like stations, airports, hospitals, etc., even with our current simulation, modeling, and data processing tools, we are only able to predict the schedules, costs, results, and consequences of the finalized building on its context in a very limited way. Growth in biology works fundamentally differently and shows qualities that could radically improve human production systems if successfully transferred. In the growth process of a plant, for example, the plant is functional from the moment the seed is laid, and during growth the plant fulfills its tasks using the local resources at hand. If a building could be used during the whole process of construction, then it could be similar to a plant; a self-growing building would be born. This is the inspirational notion for the research presented here.

The approach of biomimetics that is taken in the presented projects is seeking innovation in technology by using principles from nature, especially living organisms. Materials, structures, and processes found in role models from nature are researched, and the abstracted findings are transferred into the context of human technology [12]. As such, biomimetics is highly inter- and transdisciplinary. It is also assumed that the results of biomimetic design processes in this context provide more sustainable and ecological solutions. The methodology of bioinspired design and biomimetics has been described by different research groups and redefined in a so far unique industry standard by the German Association of Engineers (Verein Deutscher Ingenieure VDI) $[13,14]$. Biomimetics as a discipline is applied here to architecture and the arts. The overlapping fields of Biology and Architecture were investigated in previous work of the authors by applying the framework of the classical criteria of life, as stated in biology, to architecture. Analogies between biological signs of life and architectural solutions on all scales from materials to urban design were found as explained below [5].

The criterion of growth as a sign of life presented itself as one of the emerging fields of research, in addition to sensing, reacting, and evolution. Growth in biology exhibits extraordinary qualities that would be interesting for transfer into architecture and building:

- The process is the plan. Growth in biology is based on genetic code that is translated into adaptive and differentiated processing of material and structure. Genes define not only the recipes for growth but also processes that are capable of change according to the influences of the surrounding context over time. The adaptation and differentiation of organisms are linked to environmental 
parameters, controlling the expression of the growth pattern in a specific spatiotemporal context. Aspects of adaptation and differentiation could radically improve architectural materials and structures by fine tuning the use of resources to local and dynamically changing conditions. Local conditions, for example, wind load and vibration, can imply structural as well as shape adaptation, and chemical environments trigger metabolic activities. It is a more recent insight that past experiences can also shape gene expression. In this way, information on environmental conditions can be transferred over generations. This adaptiveness also relates to high resilience of the resulting structures.

- Biological growth takes on local materials and resources.

- Biological materials are produced under ambient conditions; there is no need for high energy and high temperature treatments.

- Biological structures are designed on various levels of scale, with nested structural hierarchies leading to extremely efficient, lightweight, and differentiated solutions with emergent material properties.

- Grown structures in biology are mostly fiber-based systems, integrating a range of functions; for example, integrating sensing.

- Grown structures in biology are historical; in many organisms, previous conditions and growth phases can be clearly discerned, and further growth (other than propagation) is based on existing tissue.

- Biological organisms usually are alive and grow at the same time. Functionality is maintained during growth processes.

The translation of biological growth into the fields of architecture and building has been successful on the scale of urban design, where evolutionary and optimization strategies have been introduced [15]. Digital planning and simulation especially have taken on growth strategies from biology for envisioning growth processes, including architectural design [6]. However, on the scale of buildings and materials, phenomena of growth seem to be only on the verge of being explored. Until the start of the research project GrAB in 2013, growth as an architectural strategy was still restricted to elementary extensions or deployments of already prepared building parts such as extendable roofs and platforms or to the virtual space as in Greg Lynn's seminal projects [16]. Parametric and computational design methodologies lend themselves well to reinterpreting organic design; basic principles like cellular and modular design, differentiation, and adaptation of structural principles are following deep principles found in biology $[6,11]$. On the scale of materials, for example, limited transfer in self-expanding sealants and foam structures out of polyurethane could be found. A large number of current projects in architectural design follow organic and biological morphologies [17], but many lack in depth basic scientific background and are bio-inspired rather than biomimetic in their definition $[14,18]$.

Previous work by the authors focused on biomimetics for architectural applications for outer space as well as innovation in building technologies for building envelopes [8]. In the following, the results of two research projects in the field of biomimetics are presented to discuss the field of patterns and growth from nature in architecture and the arts; 'Biornametics' [9], research on patterns from nature, and 'Growing as Building $(\mathrm{GrAB})^{\prime}$ [19], research on growth in nature translated into artistic and architectural designs. The presented projects were based at the University of Applied Art in Vienna, Austria and produced in continuous collaboration with interdisciplinary and international teams of scientists. For biomimetic transfer, a large body of scientific reference was collected, but basic biological research was also produced by the team (parts are collated and referenced in [19]; others can be found in non-public reports to the Austrian Science Foundation). The integration of basic biological research into design distinguishes our projects from many other bio-inspired design projects. As an innovation methodology, biomimetics is inherently connected to novel and emerging processing and production technologies but is also based on classical ways of scientific research as well as the design and development of technological translations. 
The research on growth patterns from nature within the frame of the research project 'Biornametics' confirmed the interest in the topic of growth. Two examples, mussel shell and banyan tree growth, are shown to illustrate the potentials of the biological role model, as well as the abstraction and transfer of ideas. These two investigations of role models and their growth behaviors created the hypothesis of more novel growth pattern translation that could be found in a further in-depth research. Therefore, the Growing as Building project was initiated to examine growing patterns and their application in architecture to create a new living architecture.

The research on growth patterns from nature had to overcome challenges in information transfer and computation. Organisms such as the giant clam and the banyan tree were exemplary role models of very different complexity for the analysis, abstraction, and simulation of growth. The shells of mussels follow simple rules of rim growth, whereas the banyan tree grows from a seed in the crown of a host tree upwards and downwards at the same time until it reaches fertile ground. Its roots adapt to the shape of the host and create a connected network of entanglement, finally strangling the host. In the scientific literature, specific and quantitative growth rules could not be found so, in order to mimic growth in simulations, growth rules were abstracted from accessible image and video material. Simulations were carried out in Rhino and Grasshopper in order to define abstracted growth rules. When the simulation matched the morphological outcome visually, the rules were assumed to be right (Figure 1). As a next step, the parameters were modified to exceed the limitations usually set in biological structures. By applying the initial growth rules and changing the parameter values beyond the biological limitations, we arrived at new sets of shape families, as shown in the simple rim growth of mussel shells (Figure 2). In this example, the growth rules defined the width of growth, translation height, and degree of curvature in relation to the previous element [9].

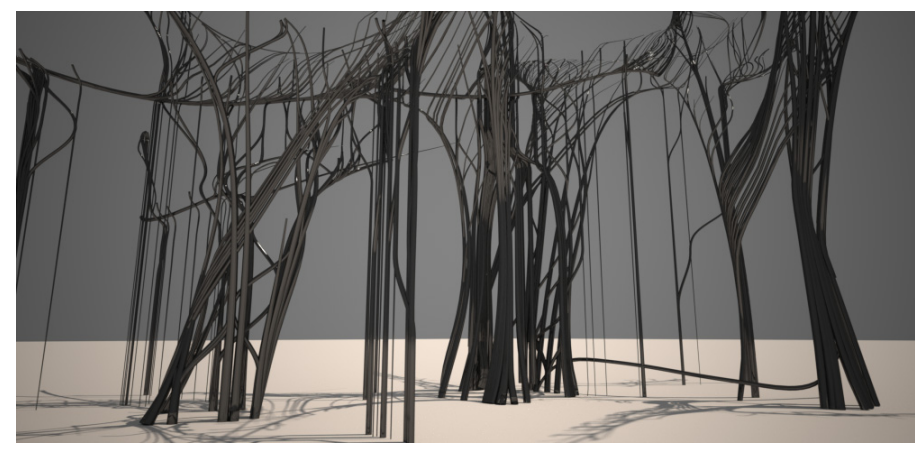

Figure 1. Simulation mimicking Banyan tree growth. CBiornametics

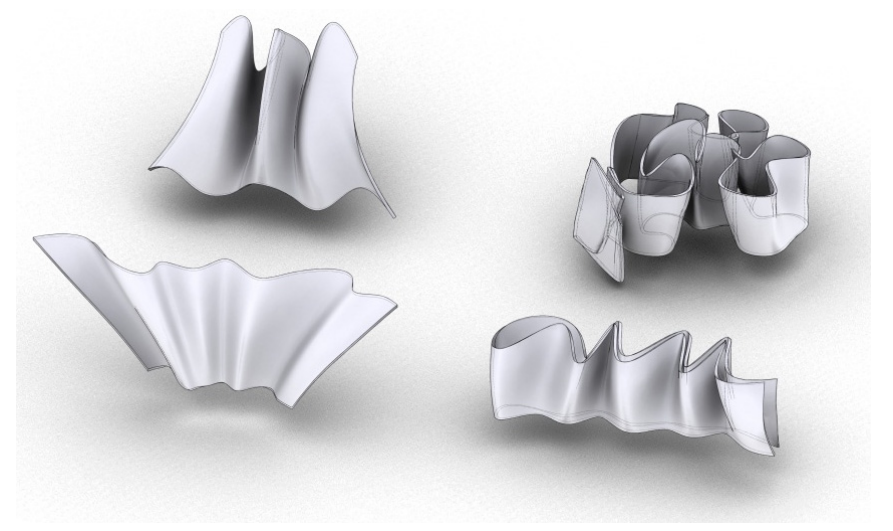

Figure 2. Objects based on mussel shell rim growth. (Biornametics

Based on the selected elementary investigations of morphogenesis in the project Biornametics, growth was further studied in the follow up project 'Growing as Building-GrAB', specifically targeting 
information transfer to building [19]. Since the harvesting of information from the biological sciences was so challenging in all precursor projects, basic scientific research and experimentation was included in $\mathrm{GrAB}$ in order to base the work on reliable observation. Thus the installation of a small do-it-yourself laboratory at the University of Applied Art, a Biolab for conservation of biological role models, biological research, and experimentation, was an integral part of the project. The main sub-goals of the project are reflected in the results of a wide range of practical experimentation:

1. Study of biological growth principles,

2. Integration of biology into material systems, and

3. Interventions in existing architecture

In the following chapters, three main threads of the project will be presented: slime mold as a co-designer (refers to sub goal 1 and 3); material systems grown from fungus mycelium on shredded recycling materials like straw, wood, and paper (refers to sub goal 2); and the further development of $3 \mathrm{D}$ printing in order to increase the range and autonomy of 3D printing (refers to sub goal 3). New production technologies are instrumental for creating a convergence between building and growing. The printing of three-dimensional elements bears analogies to biological growth. The layering of material and the differentiated addition of small elements are basic strategies that connect printing with growth.

\section{Methods and Tools}

The methodology of biomimetics describes two distinct trajectories of information flow taken from the starting point, either starting with a biological solution or a problem in technology [14]. Experience from previous work, however, shows that this differentiation is valid only as a theoretical scheme or point of departure, because most projects develop in a more ambiguous way with generic starting points and broad application fields. They also do not unfold in a linear fashion but integrate shortcuts and numerous loops of reviews feeding back to the initial intent. 'Deployable structures for a lunar base' was a good example for a theme relating the large research fields of deployable structures in biology to the design of lunar bases [20]. The workflow usually taken in biomimetic projects of research application, abstraction, was designed for the project Biornametics (pattern research) in a similar way (Figure 3) [9].

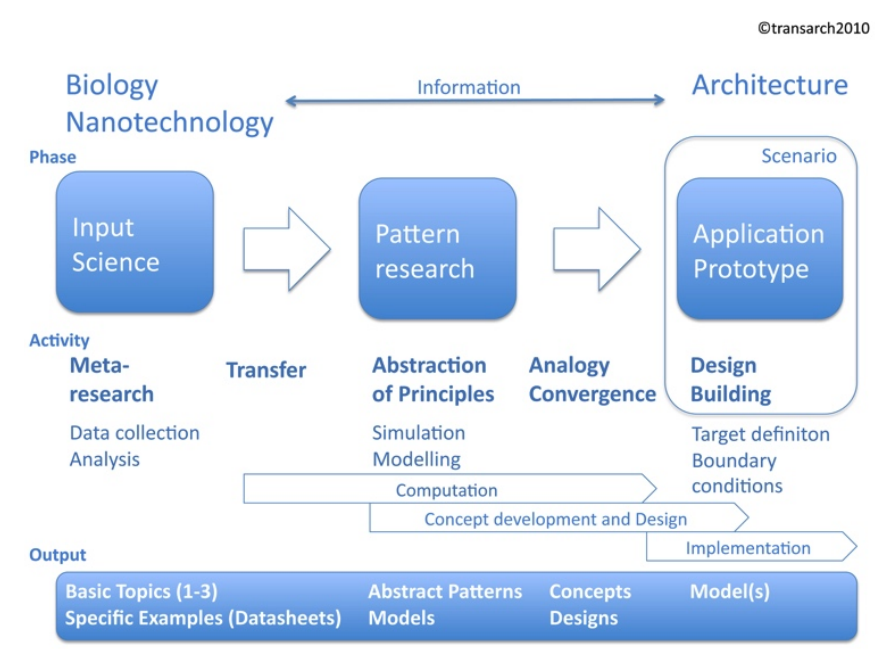

Figure 3. Study logic for biomimetics research and development.

Another challenge in biomimetic design is the selection and evaluation of the role models for further use. Since the number of principles in nature are limited but can be represented by numerous specific examples in different species, abstraction is the key to a successful allocation. In the project 'Growing as Building', a methodology from product design called 'Quality Function Deployment 
QFD' [21] was adapted to biomimetic design that allowed for faster decision making on both sides by evaluating the targets as well as the needed principles and organisms that represented them (Figure 4). The QFD helps to quantify qualitative relationships and thus supports decision making when choosing certain working paths or solution approaches to problems. The method can be applied to any topic area where there are many ideas, factors, and processes, some of which have to occur in a particular order to be of use. Any criterion can be imposed on the listed objects, processes, or concepts, producing a new list or a new order. In the case of the project on growth, four cascading sheets linked the architectural visions with functional principles and role models from nature. The sheets with 'What' and 'How' aspects were numerically evaluated for strength factor and importance. The resulting ranking was then taken further to the next level of relation. An example of a sheet relating the Architectural Wish-list with Functions in Plants is given here. The method allows comparison and integration of concepts and processes from very different areas of knowledge and technology and produces results that are useful and robust [22]. In GrAB, the QFD method resulted in a final list of role models from biology that the team agreed to work on. For reasons of accessibility and practicality, not all of them could be taken into the next project phase of cultivation in the Biolab.

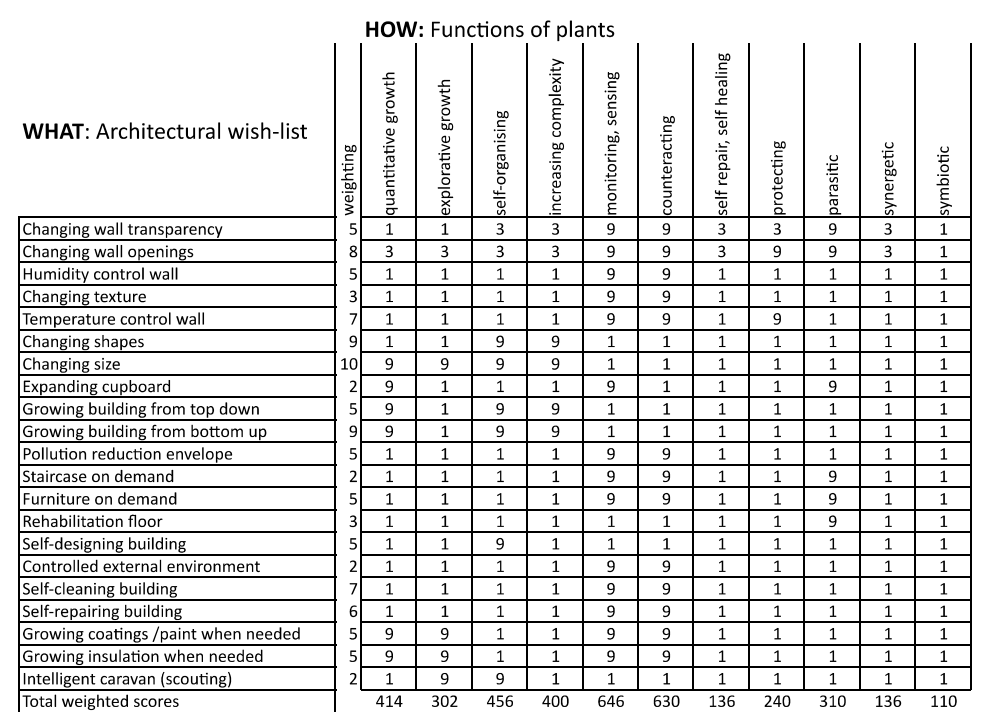

Figure 4. Quality Function Deployment QFD matrix with concepts, ranking, and data comparing architectural target concepts with botanical functions (numerical evaluation of strength of connection).

The lack of accessible biological research results experienced in precursor projects led to the introduction of a do-it-yourself biological research laboratory, supported by the biologists in the team (Figures 5 and 6). The role of the Biolab was scheduled for a limited period of time, during which organisms were cultivated and experimented with. Then the results were abstracted into architectural concepts or furthered in design research. All procedures, maintenance tasks, and observations were logged and documented. The growth patterns and growth characteristics of a range of different organisms were investigated, with a specific focus on mycelium, slime mold, and single-cell algae, as the only organisms cultivated over the full Biolab phase. Other experiments included using hydrogels to create actuated systems and the investigation of root growth and restricted growth of plants. The development of knowledge management and skills, concept observation, documentation, conceptualization of application, and production was far more challenging and interlinked than anticipated. Within the frame of the project, the role of the Biolab was redefined to the main physical project space and experimental platform that included the production of material system prototypes, design proposals based on organic matter, and even material conceptualized to be used for 3D printing. One lesson learned is that, in future similar projects, the role of a lab to experiment in basic science, as well as architectural and artistic design, should be redefined and conceptualized as a biomimetic 
fablab or makerspace. The results from the investigated selected role models, which were connected through the QFD to the architectural goals, could later be contextualized again into the original three subthemes of (1) study of biological growth principles, (2) integration of biology into material systems, and (3) interventions in existing architecture.

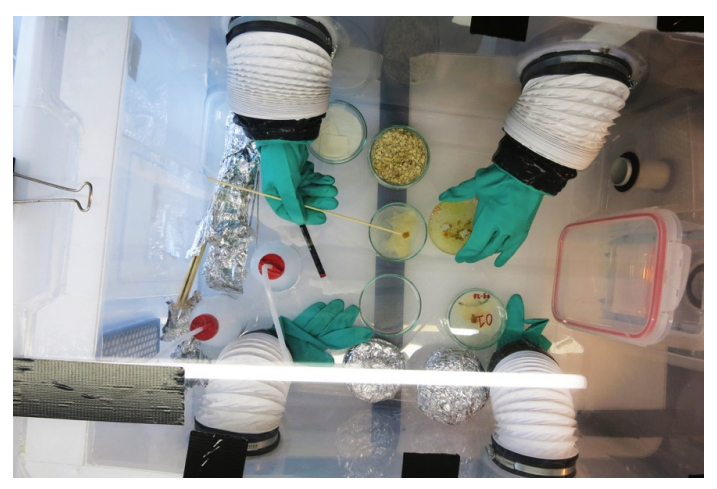

Figure 5. Glove box for cultivation of slime mold, Biolab.

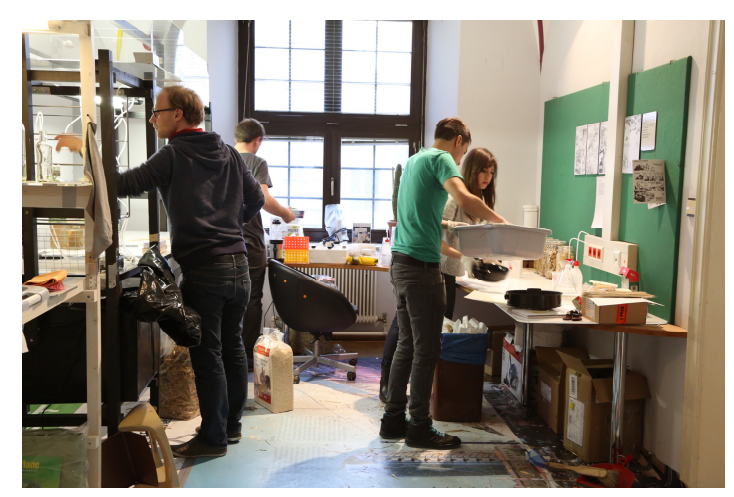

Figure 6. Project team working in the laboratory space.

\section{Results}

The three main threads of the investigations presented in the following refer to the sub-goals stated earlier, in order to start bridging the gap between growing and building. The selection of the role models was carried out in a multi stage selection process, and only the main project threads are presented in this paper. Architectural targets were defined and linked to biological principles with use of biomimetics and evaluated using a method called 'Quality function deployment QFD' adapted from product development.

\subsection{Use of Slime Mold as Co-Designer}

The capacity to explore is one of the most striking features of biological growth. Exploration is carried out to reach a suitable environment, and this phenomenon is especially interesting in the plant kingdom but also in protists. Slime mold was cultivated to research its explorative capacity. Reportedly, the collective of unicellular organisms manages to create optimized path networks when it searches for food sources. The species Physarum polycephalum was chosen for experiments in the biolab because it is a well-known model organism and has been used for many studies focusing on movement, non-muscular mobility, and its chemotactic behavior [23]. The plasmodial phase of Physarum has been applied to solve a wide range of computationally hard problems such as maze-solving, the travelling salesman problem, calculation of optimal graphs, construction of logical gates and arithmetic circuits, sub-division of spatial configurations of data points, and robot control [23]. During the foraging behavior of Physarum, which includes undirected and tree-like growth, the plasmodium 
makes blob-like colonies on sources of nutrients. The colonies are connected in a single organism by a network of protoplasmic tubes. Cytoplasm is streamed rhythmically back and forth through the network of tubular elements, circulating nutrients and chemical signals. The plasmodium propagates not only according to the position of nutrients but also in response to external gradients in light level and humidity and the general availability of water [24]. The network is considered to be optimal in terms of the efficiency of spatial covering of nutrients, sensitivity to environmental conditions, and cost-efficient transportation of nutrients and metabolites in the plasmodium's body $[25,26]$. In this research project, the Maunsell forts, historical defense structures from the Second World War in the estuaries of the river Thames in England were chosen for intervention with explorative growth (Figure 7). This project lent itself well to the design application because it consists of several defense structures that have to be internally reorganized with new functions, as well as interconnected as in their original state.

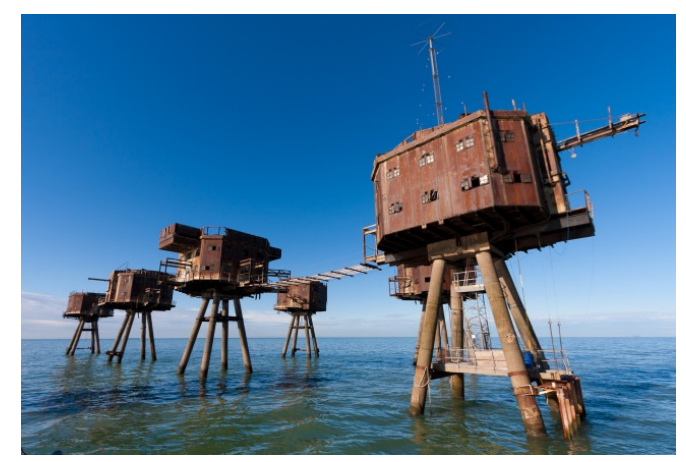

Figure 7. Maunsell Sea Fort. CC BY-SA 3.0, Wikimedia Commons.

After learning to grow the organisms in petri dishes, the team started to investigate the capacity of the slime mold to exhibit its extraordinary capacity in a three-dimensional space, which had, to the team's knowledge, never done before. Physarum was successfully grown in a three-dimensional support grid representing a scaled 1:100 model of one of the towers with food sources placed strategically on different layers (Figure 8). The fully overgrown model was scanned with a magnetic resonance imaging system and the 3D information cleaned from artifacts and noise and applied to an architectural concept with new functionality. The real growth pattern of the slime mold on the support grid was transferred into a virtual 3D model, and the connections established by the organism were translated into new architectural connections of the spaces (Figures 9 and 10). Furthermore, the whole ensemble of seven towers was envisioned as an application field for the organism's capacity to effectively explore and colonize a three dimensional space (Figure 11). In this way, slime mold was used as a co-designer to create an architectural vision for the rehabilitation and reuse of the Maunsell fort. The use of an organism for co-design in this way is called bio-utilization.

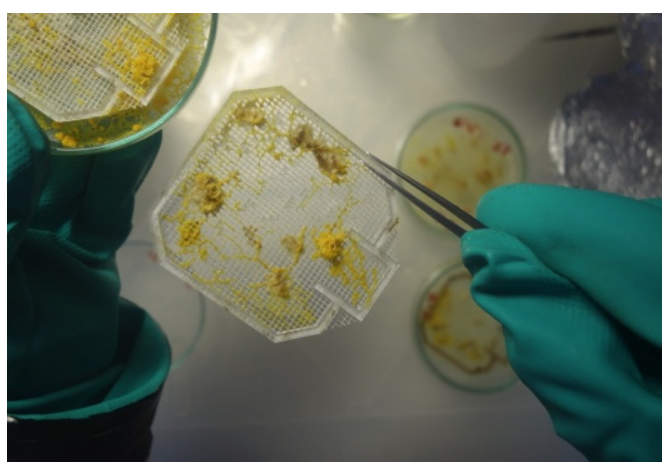

Figure 8. Documentation process of the layers. 


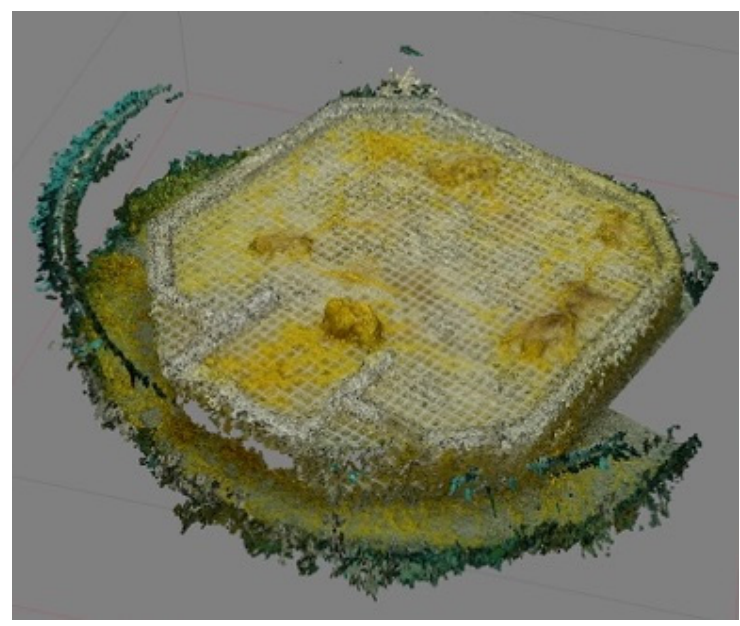

Figure 9. 3D scan of the culture.

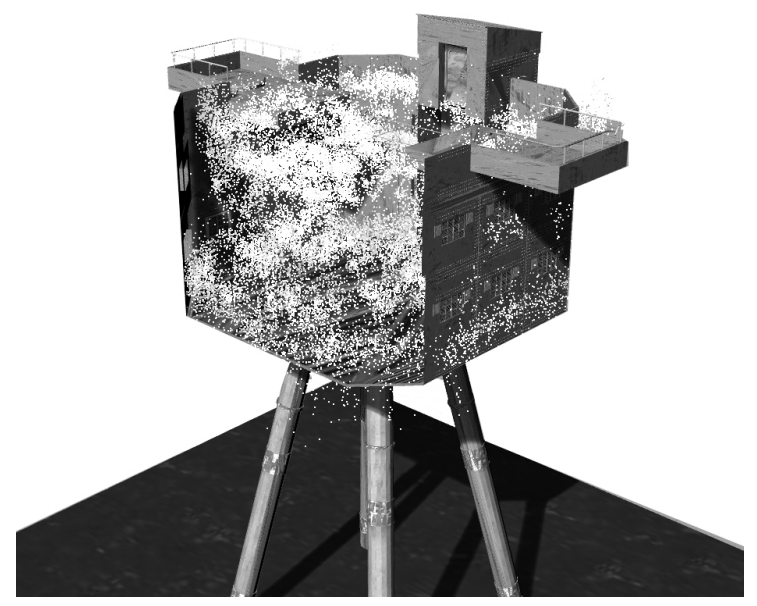

Figure 10. Point cloud data from the 3D scan arranged in a 3D model of a control tower of Maunsell Fort.

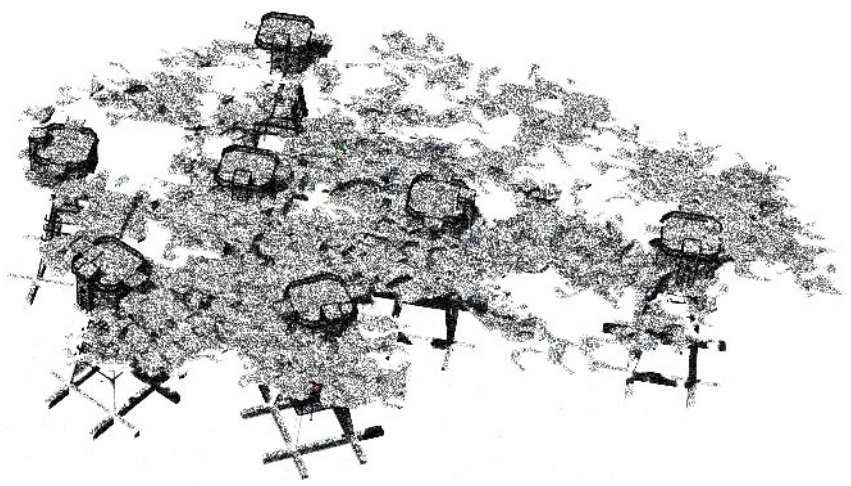

Figure 11. Slime mold growth extracted from photogrammetry and overlaid with the 3D model of the seven platforms of the Maunsell Fort.

Apart from the use of the slime mold to overgrow an architectural model of a building, the novelty of this experiment consisted of the use of a three-dimensional space grid as a base for growth. It could be shown that living slime mold grows in its optimized circulation patterns not only in $2 \mathrm{D}$ but also in 3D, allowing for efficient spatial arrangements, which can be implemented in the design of bio-inspired architecture. 


\subsection{Mycelium Material}

Existing experiments with material generated by fungus mycelium and organic waste focus on creating volumes that can be used as bricks to emulate, for example, traditional brick walls, as used for the Hi-Fi towers inside the Museum of Modern Art, New York, by 'The Living' or vault structures seen in Phil Ross' work 'Mycotecture' $[27,28]$. During the initial phase of gathering information on mycelium material, basic practical information about mycelium growth into solid matter was not publicly available despite many experiments that were carried out by various architects or artists. Therefore, an optimal growth process had to be developed together with experimentation on the templating and scaffolding. Creating and publishing the growth recipes to further future experimentation by other research groups became another goal of the project [19].

Two different species of fungi, Reishi and Oyster, were cultivated on shredded recycled materials of straw, wood, and paper. These mushroom experiments targeted the creation of solid lightweight building material and building elements out of waste products by using it as a scaffold and nourishment for the organism. As mycelium grows, this vegetative part of the fungus, consisting of a dense network of tiny threadlike elements, consolidates the fragmented substrate that it feeds on. The growth of the organism is used to create connective tissue in loose matter. As this is not a form generating process, it is necessary to introduce form before the transformation process starts. The kinds and shapes of the templates were part of the research process. Different methods for form definition and containment were explored, such as ready-made hard plastic templates, solid and modular basket-like 3D printed templates, milled styrofoam templates, gridshell systems, and soft templates out of different fabrics in different shapes (Figures 12 and 13). The first prototypes out of hard templates were problematic for a variety of reasons: the hard shell did not allow for enough gas exchange, so rotting occurred in many experiments. Templates milled out of styrofoam did also prove too airtight and maybe also thermally too well insulated, so the material started rotting. Another challenge is the shrinking of the mycelium material in the drying process, which is considerable and prevents the use of complex shapes.

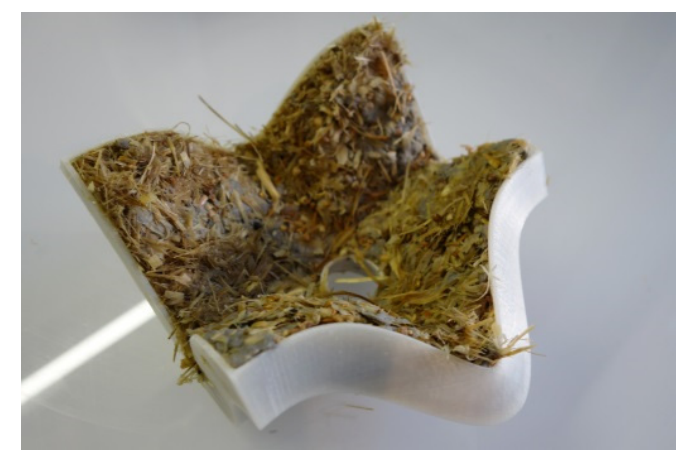

Figure 12. Mycelium material grown in hard plastic shell.

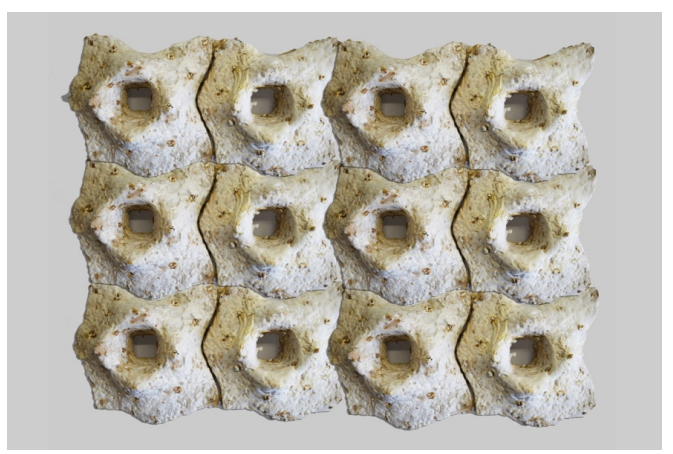

Figure 13. Modular system out of hard shell templated elements. 
Experiments with more open types of templates were more successful. As the growth of mycelium is bound to gas exchange, the diameter of the elements was limited to a few centimeters. The design of modular systems in basic elements that could connect to form architectural assemblies was one of the possible solutions, but, once fully grown and dried, elements could not be reconnected with each other and the production of columns was not possible (Figures 14 and 15).

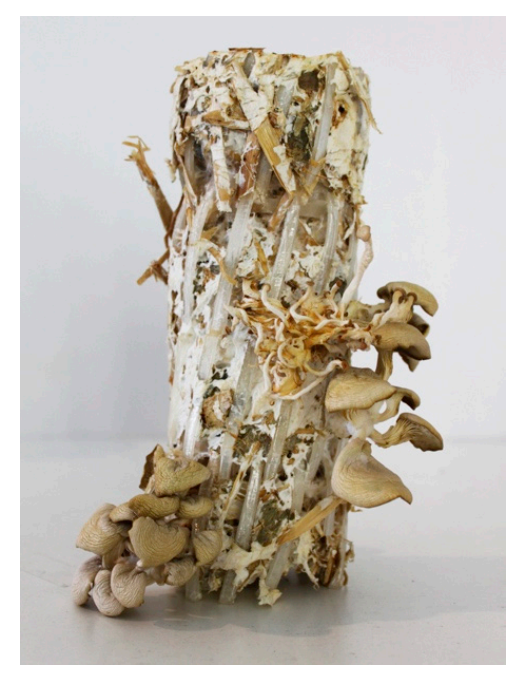

Figure 14. Interconnected 3D printed basket templates with a mycelium material system and fruiting bodies.

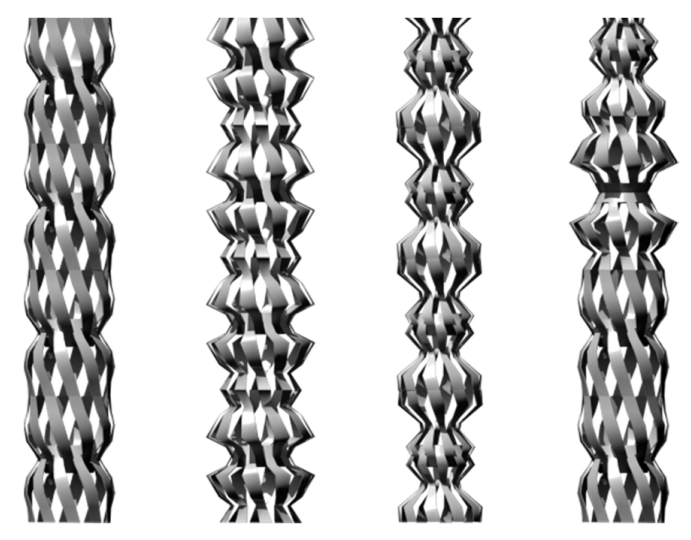

Figure 15. Possible combination of basket structures for column-like elements.

Excellent results were generated with paper grid shells that were filled with the mycelium material and fully overgrown. The openness of the system and the integration of the paper into the grown mycelium structure proved to be an efficient and promising way of templating (Figure 16).

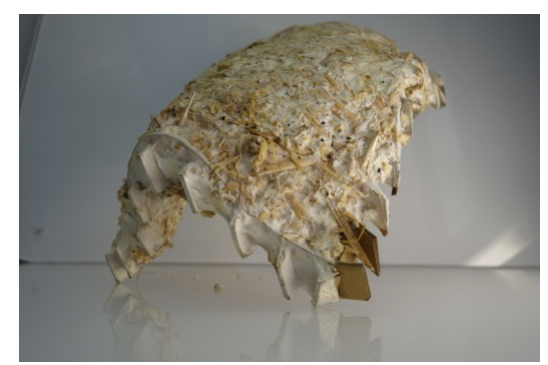

Figure 16. Possible combination of basket structures for column-like elements. 
A series of experiments with textile scaffolds were very successful. Basic cylindrical elements could be produced that were incredibly lightweight compared to their resistivity to compressive and even bending stresses.

The last development stage was textile structures, generated by tailored textile pockets, that could be used in flat states as well as in curved hanging shapes, to be turned around after drying to form a coherent shell structure (Figure 17). The size of the shell elements was about $20 \mathrm{~cm}$. In all textile experiments, the mycelium connected well with organic fabrics and the integration was very good.

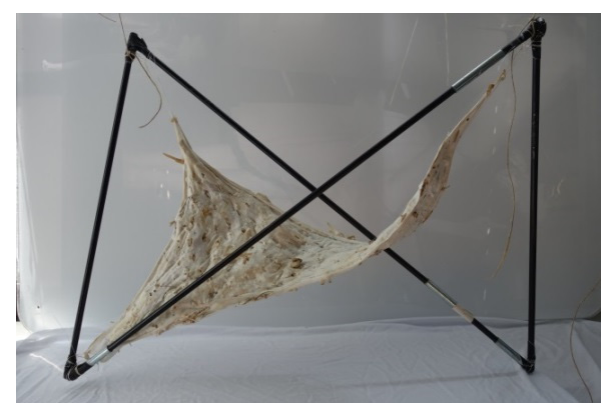

Figure 17. Triangular textile/mycelium shell.

The limitations of the mycelium material structure remain the loss of the template, the susceptibility of the material system to water, the limited size and scalability of the objects, and the long duration of the growth process of several weeks. The best growth conditions for the fungi were documented in a wide range of different experiments. The mycelium material system that was generated was also characterized by standardized material testing of simple cylindrical prototypes [19]. The structural quality of the generated material system proved to have considerable compressive strength and impact resistance similar to the wood of a willow.

The basket and textile scaffold the team developed are novel ways to produce mycelium material elements on an architectural scale, going beyond existing projects with solid templates. Especially, the textile shells seem very promising and are worth further research and development in a future project. In the project thread 'mycelium material', a material system was produced by using the growth of an organism. This can be seen as bio-utilization but can also be interpreted as a way to establish structural hierarchy and, in this way, as using an abstract biomimetic principle.

\subsection{Free Print Head}

3D printing was used in the other experiments as a standard tool for creating growth templates and scaffolds. The integration of 3D printing as an important research thread refers to the idea of swarming exploring building agents. The vision of small swarming printing devices also traces back to the Biornamtics project on patterns and the role model of swarms in biology. Autonomous, intelligent, and swarming building agents capable of self-building and self-design could address many of the architectural targets that were defined in $\mathrm{GrAB}$ as a wish list for the future, including the self-growing house. A first step towards the direction of autonomously ranging agents was to free the printer from its case and extend the locomotion space. The development of appropriate controlling algorithms has opened up the possibility of using wire robots in wide segments of industry from forklift robots to the control of the feed system for large spherical radio telescopes $[29,30]$. Cable driven systems, taking on existing technology for wire robots, might not be a way to generate enough freedom for swarm architecture, but, in the context of adding material to already present existing architecture, this technology provides a viable and flexible enough way to create intervention. The main advantages of such systems are the lightweight design and flexibility in transport and deployment. Two different systems of cable driven 3D printers were developed, parallel and star cable printers, that focused on the device as well as the printed item (Figures 18-20). The size of the printers occupied a space of 
approximately $4 \mathrm{~m} \times 5 \mathrm{~m}$ and about $3 \mathrm{~m}$ in height. The actual building area was about four cubic meters, and the actually printed objects with the parallel cable printer reached about $60 \mathrm{~cm}$ in height. Due to the cable suspensions, the accuracy of the printers did not reach the quality of conventional printers and vibrations in the environment were also transferred to the printed object. In addition to the technical development of the printers and printheads, a concept for a new extrusion material based on calcium carbonate was created out of the metabolic system of algae growth, linking to another experimental setup that is not described in this paper [19]. The $\mathrm{CO}_{2}$ output of the calcium carbonate $3 \mathrm{D}$ printer is sequestered by using it to grow algae, and the algae can then be used to generate ethanol and acetic acid, two components of the printing material. The star cable printer was developed to integrate a material tank and control the angle of the print head. Cable-driven 3D printers are a very promising method of integrating bio-inspired feedback loops and interactions with the environment into the architectural prototyping process. Further research in dynamic behavior and an extension in sensor capacities would complement the already existing advantages.

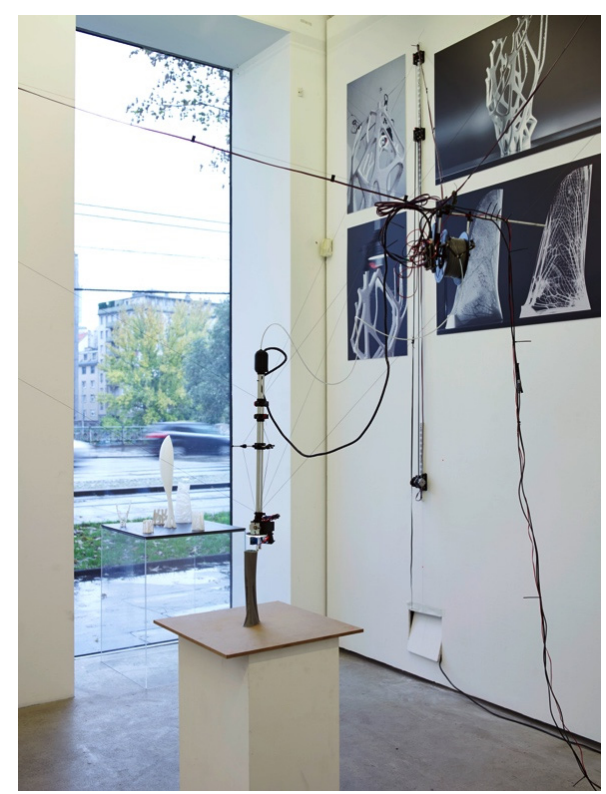

Figure 18. Parallel cable printer installed in the exhibition space. (c) Bruno Stubenrauch.

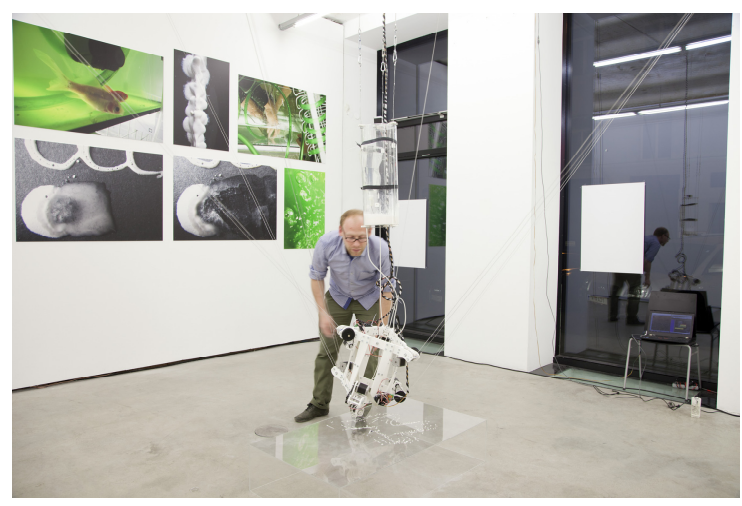

Figure 19. Star cable printer installed in the exhibition space. ㅇ Bruno Stubenrauch. 


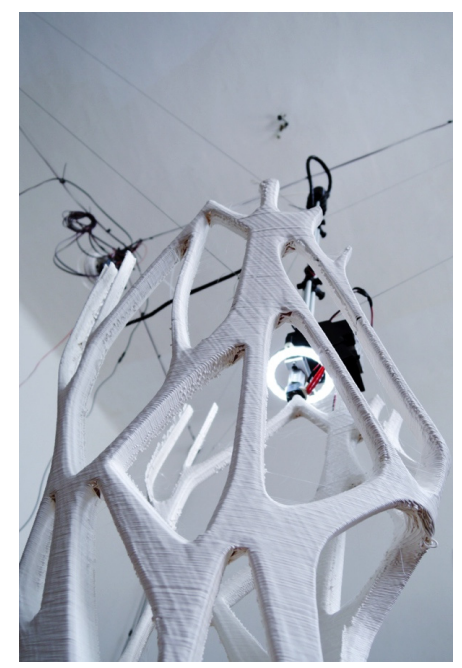

Figure 20. Parallel cable printer processing large object.

\section{Discussion}

This wide range of experiments was carried out in order to integrate principles of growth into proto-architecture and design concepts, with a diversity of outcomes referring to the project goals. The described experiments deliver steps on the way to embody aspects of growth into architectural prototyping, with the reuse of material in a lightweight material system, efficient pathfinding by organismic co-design, and improved 3D printing tools leading to a more sustainable approach to generate design and buildings. The outcomes of the experimentation were presented to the public in an exhibition (Figure 21) and a book publication. During the project duration, panel discussions with international guests were organized to involve a public audience. Together with the role of new technologies in innovative design, the role of organisms within the design and production processes was discussed. Ethical questions were raised about the use of living organisms in bio-utilization or as co-designers. Cultivating even simple organisms and research into growth principles turned out to be extremely challenging in a do-it-yourself-setup. The creation of controlled environments is a precondition for targeted biological growth procedures. Digital processes, tools, and analogue experimentation were equally important in alternately driving research and development in the projects. The challenges perceived in this project will be taken on to further develop a concept for integrating biomimetics into a makerspace and a biology laboratory and for extending the fabrication side for basic research and abstraction activities.

Challenges in the application of biomimetics in design still have to be overcome, and computational solutions could be of great help. In the starting phase of any project, sourcing of information from biology is a challenge. This is due to the fact that different cultures of knowledge production constrain information flow between fields but is also due to the nature of the information that is produced and published. Descriptive information from the life sciences stands in stark contrast to specific functional interests from the design side. Biological organisms deliver an abundance of interesting and multifunctional solutions so that the allocation of keywords or deeper principles in databases often only superficially relates to the interest. Within the frame of precursor projects, a large number of intriguing aspects of biological role models were identified, but no scientific literature could be found. Currently available databases and tools, for example, 'Ask Nature' [31] published by the Biomimicry Group, lack specific information or provide only superficial descriptions. However, both issues, within their limits, still represent starting points for functional research in biomimetics. To overcome the gaps, more causal information would have to be produced and made available so that a sensible mapping to technical interests could be found, going beyond the capacity of currently available databases and catalogues. Ontologies could be a way forward but have yet to be developed [32]. 
For the pattern research project, information on a large number of role models and phenomena was processed into datasheets that equipped designers with sufficient information to know about the basic principles and led further to expert information. For the design process, categorization into functional groups was used, which attributed the biological examples to different potentials for translation. The functional groups were later used in design workshops to guide combinations of solutions to integrated concepts. Although those tools were developed in an analogue way and datasets were set up within the frame of specific projects, the methodology was step by step refined and again applied in the GrAB project.

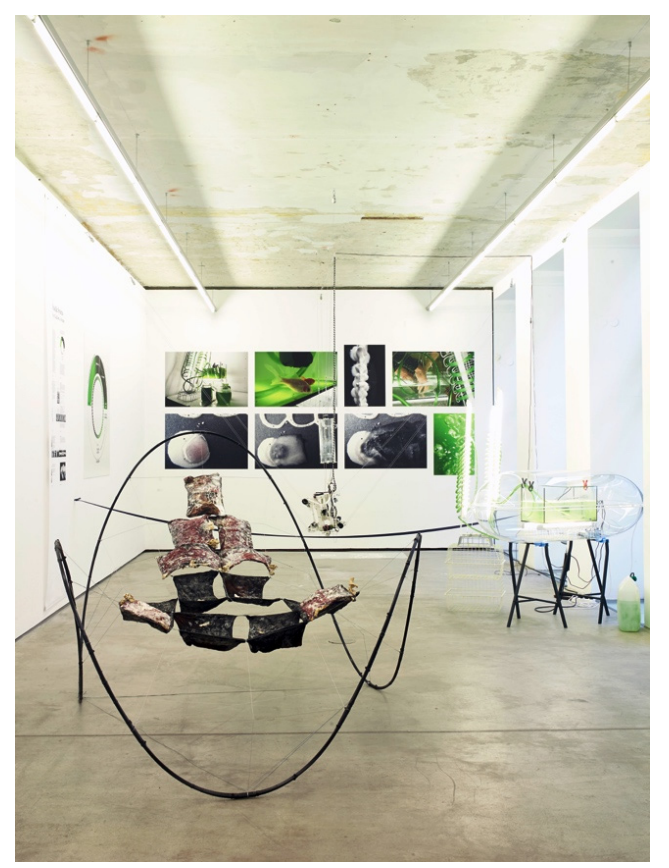

Figure 21. Exhibition October 2015, with mycelium material grown in textile shapes in the foreground and an algae bioreactor and cable printer in the background. (C) Bruno Stubenrauch.

\section{Conclusions}

The set-up of the project Growing as Building requested a highly interdisciplinary team that allowed a wide range of investigations. Biologists of different biological disciplines ranging from botany to ecology and micro-biology, robotics engineers, architects, designers, and artists collaborated to work with the slime-mold as co-designer, investigate material systems with mycelium, and translate growth into novel 3D mobile printers. The slime mold experiments looked at the organisms' network creation within a three-dimensional space grid, thus taking existing research a step further and showing how the slime could adopt this specific space-grid environment. Its capabilities lead the researchers to the assumption that these space-grid networks formed by the slime mold makes it the co-designer of design concepts. With the second field of investigation, the material systems, the textile scaffolds that also proved to be very successful were specifically new. Tailored textile pockets were filled with mycelium and both substrates grew together so that the dried hanging parabolic textile shapes could be turned 180 degrees and function as coherent shell structures like vaults. Finally, the third investigation was 3D printing, one of the disruptive technologies. The cable driven printers were novel at their time in 2015, and their main advantages are the lightweight design and flexibility in transport and deployment. The star-cable printer printed with a material based on calcium carbonate, which was part of a bioreactor loop with algae, bio-mass, and oxygen production. This Bioreactor loop was only created on a concept level to show how a printer material with calcium carbonate could become part of a larger ecosystem loop. 
The presented projects, especially in the selected research threads, demonstrate the furthering of knowledge about tmaterial systems, transfer strategies, and production tools. New pathways for further research and future projects taking architectural design closer to biological growth were laid with the described experiments. The open access policy that the authors took on for the project's results allows for other researchers to learn from the GrAB experiments and build on this knowledge in their own projects.

A direct offspring of the project Growing as Building in the domain of biomimetic architecture is the project 'Living Architecture (LIAR)', in which GrAB team members integrate metabolic activity as a permanent state into functional architectural elements. LIAR is a three-year project and is funded by the European Commission through the program 'Future and Early Technologies (FET)', addressing early stage science and technology research exploring new foundations for radically new future technologies by challenging current paradigms and venturing into unknown areas [33]. The project 'Living Architecture' aims at transforming our habitats from inert spaces into programmable sites through designing and developing units with microbial fuel cells and synthetic microbial consortia cleaning water and air as an integral part in our households and buildings. The project Living Architecture started in April 2016 and will terminate with a prototype in March 2019.

Acknowledgments: Acknowledgements go to our project partners and collaborating scientists: Greg Lynn, Georg Gläser, Arne Hofmann, Ille C. Gebeshuber, George Jeronimidis, Julian Vincent, Thomas Speck, Angelo Vermeulen, Rachel Armstrong, Waltraut Hoheneder, Clemens Grünberger, Damjan Minovski, Viktor Gudenus and Tanja Oberwinkler; student researchers: Moritz Dörstelmann, Rangel Karaivanov, Joseph Hofmarcher, Kourosh Asgar-Irani, Bika Sibila Rebek, Josip Bajecer, Lisa Sommerhuber, Natasha Chayaamor, Andreas Körner, Rafael Sánchez Herrera, Ceren Yönetim, Laura Mesa Arango, Mariya Korolova, Atanas Zhelev, Ioana Binica, Alexander Nanu, and Mohammedneja Shikur; the University of Applied Arts in Vienna. The presented projects were funded by the Austrian Science Fund FWF under the Program for Arts-based Research PEEK.

Author Contributions: Barbara Imhof and Petra Gruber were co-project leaders in the projects and collaborated in writing the paper. The forementioned project partners and students collaborated in designing and performing the experiments.

Conflicts of Interest: The authors declare no conflict of interest.

\section{References}

1. Badura, J. Explorative practices in dialogue. Art-based research at the interface of arts, sciences, and design. In What Is the Architect Doing in the Jungle? Biornametics; Imhof, B., Gruber, P., Eds.; Edition Angewandte; Springer: Wien, Austria, 2013; pp. 14-19.

2. Bushan, B. Biomimetics: Lessons from Nature-An Overview. Philos. Trans. R. Soc. A 2009, 367, 1445-1486. [CrossRef] [PubMed]

3. Bar-Cohen, Y. (Ed.) Biomimetics Nature-Based Innovation; Taylor \& Francis: Boca Raton, FL, USA, 2012.

4. Goel, A.; McAdams, D.A.; Stone, R.B. Biologically Inspired Design—Computational Methods and Tools; Springer: London, UK, 2014.

5. Gruber, P. Biomimetics in Architecture - Architecture of Life and Buildings; Springer: Wien, Austria, 2011.

6. Schumacher, P. (Ed.) Parametricism 2.0: Rethinking Architecture's Agenda for the 21st Century. In Architectural Design AD Special Issue; Wiley: London, UK, 2016.

7. Gruber, P.; Jeronimidis, G. Has biomimetics arrived in architecture? Bioinspir. Biomim. 2012, 7, 010201. [CrossRef] [PubMed]

8. Gruber, P.; Imhof, B. Transformation: Structure/space studies in bionics and space design. Acta Astronaut. 2007, 60, 561-570. [CrossRef]

9. Imhof, B.; Gruber, P. (Eds.) What Is the Architect Doing in the Jungle? Biornametics; Edition Angewandte; Springer: Vienna, Austria, 2013.

10. Hensel, M.; Menges, A. (Eds.) Morpho-Ecologies: Towards Heterogeneous Space in Architecture Design; AA Publications: London, UK, 2007. 
11. Gangolells, M.; Casals Casanova, M.; Gassó Domingo, S.; Forcada Matheu, N.; Roca Ramon, X.; Fuertes Casals, A. A methodology for predicting the severity of environmental impacts related to the construction process of residential buildings. Build. Environ. 2009, 44, 558-571. [CrossRef]

12. Aunger, R. What's special about human technology? Camb. J. Econ. 2010, 34, 115-123. [CrossRef]

13. Vattam, S.; Helms, M.E.; Goel, A. Biologically Inspired Innovation in Engineering Design: A Cognitive Study; Technical Report; Graphics, Visualization and Usability Center, Georgia Institute of Technology: Atlanta, GA, USA, 2007.

14. VDI (Verein Deutscher Ingenieure) Guideline 6220. Biomimetics-Conception and Strategy Differences between Bionic and Conventional Methods/Products; Verein Deutscher Ingenieure: Düsseldorf, Germany, 2011.

15. Pedersen Zari, M. Ecosystem processes for biomimetic architectural and urban design. Archit. Sci. Rev. 2015, 58, 106-119. [CrossRef]

16. Lynn, G. Animate Form; Princeton: New York City, NY, USA, 1999.

17. Kuhlmann, D. Biomorphism in Architecture: Speculations on Growth and Form. In Biomimetics-Materials, Structures and Processes; Gruber, P., Bruckner, D., Hellmich, C., Schmiedmayer, H.B., Stachelberger, H., Gebeshuber, I.C., Eds.; Springer: Berlin/Heidelberg, Germany, 2011.

18. Speck, O.; Speck, D.; Horn, R.; Gantner, J.; Sedlbauer, K.P. Biomimetic bio-inspired biomorph sustainable? An attempt to classify and clarify biology-derived technical developments. Bioinspir. Biomim. 2017, 12, 011004. [CrossRef] [PubMed]

19. Imhof, B.; Gruber, P. (Eds.) Built to Grow: Blending Architecture and Biology; Edition Angewandte; Birkhäuser: Basel, Switzerland, 2015.

20. Gruber, P.; Häuplik, S.; Imhof, B.; Özdemir, K.; Waclavicek, R.; Perino, M.A. Deployable Structures for a Human Lunar Base. Acta Astronaut. 2007, 61, 484-495. [CrossRef]

21. Prasad, B. Review of QFD and related deployment techniques. J. Manuf. Syst. 1998, 17, 221-234. [CrossRef]

22. Vincent, J.F.V.; Vermeulen, A. Methods of Science in Art. In Built to Grow: Blending Architecture and Biology; Imhof, B., Gruber, P., Eds.; Edition Angewandte; Birkhäuser: Basel, Switzerland, 2015.

23. Aono, M.; Hara, M.; Aihara, K.; Munakata, T. Amoeba-based emergent computing: Combinatorial optimization and autonomous meta-problem solving. Int. J. Unconv. Comput. 2009, 6, 89-108.

24. De Lacy Costello, B.; Adamatzky, A. Routing of Physarum polycephalum "signals" using simple chemicals. Commun. Integr. Biol. 2014, 7, e28543. [CrossRef] [PubMed]

25. Nakagaki, T.; Yamada, H.; Ueda, T. Interaction between Cell Shape and Contraction Pattern in the Physarum Plasmodium. Biophys. Chem. 2000, 84, 195-204. [CrossRef]

26. Nakagaki, T.; Yamada, H.; Tóth, A. Path Finding by Tube Morpho-genesis in an Amoeboid Organism. Biophys. Chem. 2001, 92, 47-52. [CrossRef]

27. A Project by The Living. Available online: http://thelivingnewyork.com/hy-fi.htm (accessed on 15 August 2015).

28. Mycotecture. Available online: http:// philross.org (accessed on 15 August 2015).

29. Bruckmann, T.; Pott, A. Cable-Driven Parallel Robots; Springer: Berlin/Heidelberg, Germany, 2013.

30. Su, Y.X.; Duan, B.Y. Mechanical Design and Kinematics Accuracy Analysis of a Fine Tuning Stable Platform for the Large Spherical Radio Telescope. Mechatronics 2000, 10, 819-834. [CrossRef]

31. Ask Nature. Available online: http:/ / www.asknature.org (accessed on 15 August 2015).

32. Vincent, J.F.V. An Ontology of Biomimetics. In Biologically Inspired Design, Computational Methods and Tools; Goel, A.K., McAdams, D.A., Stone, R.B., Eds.; Springer: London, UK, 2014; pp. 269-285.

33. Horizon 2020-EU, FET Open. Available online: http://cordis.europa.eu/programme/rcn/664103_en.html (accessed on 5 March 2017).

(C) 2017 by the authors. Licensee MDPI, Basel, Switzerland. This article is an open access article distributed under the terms and conditions of the Creative Commons Attribution (CC BY) license (http:/ / creativecommons.org/licenses/by/4.0/). 